\title{
The Revascularization Scales Dilemma: Is It Right to Apply the Treatment in Cerebral Ischemia Scale in Posterior Circulation Stroke?
}

\author{
(D) C. Jung, (DW. Yoon, (DS.J. Ahn, DB.S. Choi, DJ.H. Kim, and (D) S.H. Suh
}

\begin{abstract}
BACKGROUND AND PURPOSE: Although various revascularization scales are used in the angiographic evaluation of acute ischemic stroke, observer reliability tests of these scales have been rarely performed for posterior circulation stroke. We aimed to evaluate interand intraobserver variability of 2 scales, the modified Treatment in Cerebral Ischemia and the Arterial Occlusive Lesion, in posterior circulation stroke.
\end{abstract}

MATERIALS AND METHODS: Three independent readers interpreted pre- and postthrombolytic angiographies of 62 patients with posterior circulation stroke by using the modified Treatment in Cerebral Ischemia and Arterial Occlusive Lesion scales. The $\kappa$ statistic was used to measure observer agreement for both scales, and $\kappa>0.6$ was considered substantial agreement.

RESULTS: For the Arterial Occlusive Lesion scale, inter- and intraobserver agreement was $>0.6$. While intraobserver agreement of the modified Treatment in Cerebral Ischemia scale was $>0.6$ except for 1 reader, interobserver agreement was lower in dichotomized and original scales. In 49 cases with solely basilar artery occlusion, inter- and intraobserver agreement of both scales was similar to that in all 62 patients with posterior circulation stroke. In 2 consecutive readings, there was a significant decrease in the proportion of $\mathrm{mTICI} 2 \mathrm{a}$ reads (22.58\% in the first versus $13.44 \%$ in the second session, $P<.03$ ) and a reciprocal increase in the sum of proportions for modified Treatment in Cerebral Ischemia $2 \mathrm{~b}$ and modified Treatment in Cerebral Ischemia 3 reads $(62.37 \%$ in the first versus $72.58 \%$ in the second session, $P<$ .046).

CONCLUSIONS: In angiographic assessment of posterior circulation stroke, inter- and intraobserver agreement for the Arterial Occlusive Lesion scale was reliable, while the modified Treatment in Cerebral Ischemia failed to achieve substantial interobserver agreement. The clinical impact of this result needs to be validated in future studies.

ABBREVIATIONS: $\mathrm{AOL}=$ Arterial Occlusive Lesion; $\mathrm{BAO}=$ basilar artery occlusion; $\mathrm{mTICI}=$ modified Treatment in Cerebral Ischemia; $\mathrm{TICI}=\mathrm{Thrombolysis}$ in Cerebral Infarction; TIMI = Thrombolysis in Myocardial Infarction

In the treatment of acute ischemic stroke with large intracranial arterial occlusion, endovascular techniques are becoming the mainstream with higher revascularization rates. ${ }^{1-3}$ While various grading schemes, such as the Thrombolysis in Myocardial Infarction (TIMI) or Thrombolysis in Cerebral In-

Received June 3, 2015; accepted after revision July 22.

From the Department of Radiology (C.J., B.S.C., J.H.K.), Seoul National University College of Medicine, Seoul National University Bundang Hospital, Seongnam, Korea; Department of Radiology (W.Y.), Chonnam National University Medical School, Gwangju, Korea; Department of Radiology (S.J.A., S.H.S.), Gangnam Severance Hospital, Yonsei University, Seoul, Korea; and Severance Institute of Vascular and Metabolic Research (S.H.S.), Yonsei University College of Medicine, Seoul, Korea.

This study was supported by a faculty research grant from Yonsei University College of Medicine (6-2015-0051).

Please address correspondence to Sang Hyun Suh, MD, Department of Radiology, Gangnam Severance Hospital, Yonsei University College of Medicine, 712 Eonjooro, Gangnam-gu, Seoul, 135-720 Korea; e-mail: suhsh11@yuhs.ac

http://dx.doi.org/10.3174/ajnr.A4529 farction (TICI), are widespread, their reliability in angiographic assessment of anterior circulation stroke remains controversial. $^{4-8}$ Recently, the modified Treatment in Cerebral Ischemia (mTICI) and the Arterial Occlusive Lesion (AOL) scales were strongly recommended as standards of reperfusion and recanalization in the angiographic evaluation of anterior circulation stroke. ${ }^{9}$

Despite applying similar scales to the posterior circulation, it is also unclear which scales might be reliably implemented for the vertebrobasilar territory. Recently, Gerber et $\mathrm{al}^{10}$ questioned whether it is right to use the TIMI or TICI scale in posterior circulation stroke and demonstrated that interobserver variability tests of these scales had never been performed in case of posterior circulation stroke.

Therefore, we aimed to evaluate intra- and interobserver agreement of the mTICI and AOL scales in the angiographic evaluation of posterior circulation stroke. 
Table 1: The modified Treatment in Cerebral Ischemia and the Arterial Occlusive Lesion scale scores

\begin{tabular}{|c|c|c|c|c|c|}
\hline & \multicolumn{3}{|c|}{$\mathrm{mTICl}$} & \multicolumn{2}{|c|}{$\mathrm{AOL}$} \\
\hline 0 & \multicolumn{3}{|c|}{ No perfusion } & \multicolumn{2}{|c|}{ Complete occlusion of the target artery } \\
\hline 1 & \multirow{2}{*}{\multicolumn{3}{|c|}{$\begin{array}{l}\text { Antegrade reperfusion past the initial occlusion but limited } \\
\text { distal branch filling with little or slow distal reperfusion }\end{array}$}} & \multirow{2}{*}{\multicolumn{2}{|c|}{$\begin{array}{l}\text { Incomplete or partial local recanalization at the } \\
\text { target artery with no distal flow } \\
\text { Incomplete or partial local recanalization at the } \\
\text { target artery with any distal flow }\end{array}$}} \\
\hline 2 & & & & & \\
\hline $2 a$ & \multicolumn{5}{|c|}{$\begin{array}{l}\text { Antegrade reperfusion of less than half of the previously occluded } \\
\text { target artery ischemic territory }\end{array}$} \\
\hline $2 b$ & \multicolumn{5}{|c|}{$\begin{array}{l}\text { Antegrade reperfusion of more than half of the previously occluded } \\
\text { target artery ischemic territory }\end{array}$} \\
\hline 3 & \multicolumn{3}{|c|}{$\begin{array}{l}\text { Complete antegrade reperfusion of the previously occluded target artery } \\
\text { territory, with absence of visualized occlusion in all distal branches }\end{array}$} & \multicolumn{2}{|c|}{$\begin{array}{l}\text { Complete recanalization and restoration of the } \\
\text { target artery with any distal flow }\end{array}$} \\
\hline & & \multicolumn{4}{|c|}{$\kappa$ Values (SE) } \\
\hline & & \multicolumn{2}{|c|}{ Original Scale } & \multicolumn{2}{|c|}{ Dichotomized Scale } \\
\hline \multicolumn{2}{|c|}{ Reader } & All $(N=62)$ & BAO $(n=49)$ & All $(N=62)$ & BAO $(n=49)$ \\
\hline \multicolumn{6}{|c|}{$\mathrm{mTICl}$} \\
\hline & us $B$ & $0.418(0.088)$ & $0.43(0.093)$ & $0.315(0.116)$ & $0.334(0.131)$ \\
\hline & us $C$ & $0.484(0.074)$ & $0.471(0.082)$ & 0.506 (0.111) & $0.469(0.126)$ \\
\hline & us C & $0.503(0.077)$ & $0.523(0.08)$ & $0.478(0.11)$ & $0.466(0.121)$ \\
\hline \multicolumn{6}{|c|}{$\mathrm{AOL}$} \\
\hline & us $B$ & $0.696(0.089)$ & $0.7(0.091)$ & $0.815(0.127)$ & $0.810(0.130)$ \\
\hline & us $C$ & $0.631(0.086)$ & $0.659(0.088)$ & $0.742(0.142)$ & $0.734(0.145)$ \\
\hline & us C & $0.709(0.081)$ & $0.775(0.075)$ & $0.914(0.085)$ & $0.911(0.087)$ \\
\hline
\end{tabular}

Note:-SE indicates standard error.

\section{MATERIALS AND METHODS \\ Patients}

After approval of the institutional review board for this retrospective study, 62 patients (men/women $=37: 25$, mean age $=68 \pm$ 11.4 years) with acute posterior circulation stroke, who underwent intra-arterial thrombolysis from April 2004 to December 2013, were consecutively enrolled from a single institutional data base. All patients underwent digital subtraction angiography before and after the procedure.

In these patients, the mean NIHSS score at admission was $17 \pm 8$, and the levels of arterial occlusion in the basilar $(n=49)$ and vertebral arteries $(n=13)$ were $79 \%$ and $21 \%$, respectively. At 3 months, 21 patients (33.9\%) had a good outcome (modified Rankin Scale score 0-2) and 12 (19\%) had died.

\section{Image Acquisition}

DSA images from angiograms of the bilateral vertebral arteries were acquired by using a biplane angiography system. Consecutive anteroposterior and lateral angiographic images before and after intra-arterial thrombolysis, from the arterial to the delayed venous phase, were obtained in JPEG format, and were converted to a movie file format (Adobe Flash authoring file). Each reader interpreted them via on-line storage by making a comparison between preoperative and postoperative DSA images.

\section{Image Interpretation}

Three experienced readers (S.H.S., C.J., and W.Y.), who worked in 3 different tertiary medical centers as interventional neuroradiologists (with $>10$ years of experience), independently reviewed all images of 62 cases twice, 3-4 months apart. There was no training or required consensus of readers to perform this task.
Regardless of the others' reads, each reader assessed his own read by using the mTICI and AOL scales. In Table 1, the mTICI scale is defined in 5 grades according to the Stroke Treatment Academic Industry Roundtable consensus ${ }^{9}$ and the AOL scale is classified into 4 grades. ${ }^{11}$ For this study, we did not provide any special information to the readers.

\section{Statistical Analysis}

As parameters of intraobserver and interobserver agreement, the $\kappa$ statistic was used for the mTICI and AOL scales. The $\kappa$ value was interpreted according to Landis and $\mathrm{Koch}^{12}$ with a $\kappa$ value of $0=$ poor, $0.01-0.20=$ slight, $0.21-0.40=$ fair, $0.41-0.60=$ moderate, $0.61-0.80$ substantial, and $0.81-1.0=$ almost-perfect agreement. The $\kappa$ statistic was also calculated for 49 cases with basilar artery occlusion (BAO) and the dichotomized groups, including those with poor revascularization $(\mathrm{AOL}=0-2, \mathrm{mTICI}=0-2 \mathrm{a})$ versus good revascularization $(\mathrm{AOL}=3, \mathrm{mTICI}=2 \mathrm{~b}-3)$. Comparison of the $\kappa$ values was performed by using $95 \%$ CIs for the difference between the $\kappa$ statistics, with 1000 bootstrapped samples. The difference was statistically significant if $95 \%$ CIs did not include zero. Statistical analyses were performed by using SAS (Version 9.2; SAS Institute, Cary, North Carolina).

\section{RESULTS}

Contrary to the AOL scale, all pair-wise $\kappa$ values for the mTICI were lower than 0.6 in interobserver agreement (Table 2). Intraobserver agreement for the AOL and mTICI scales was substantial to almost perfect in most cases, except for 1 reader for the mTICI scale (reader A, $\kappa=0.444$ in all and 0.462 in BAO, respectively; Table 3). Regardless of the scale used, intraobserver and interob- 
Table 3: Intraobserver agreement between 62 cases and subset of 49 cases with basilar artery occlusion

\begin{tabular}{|c|c|c|c|c|c|c|}
\hline \multirow[b]{3}{*}{ Scale } & \multicolumn{6}{|c|}{$\kappa$ Values (SE) } \\
\hline & \multicolumn{3}{|c|}{ All $(N=62)$} & \multicolumn{3}{|c|}{ BAO $(n=49)$} \\
\hline & Reader A & Reader B & Reader C & Reader A & Reader B & Reader C \\
\hline $\mathrm{mTICl}$ & $0.444(0.085)$ & $0.79(0.061)$ & $0.855(0.045)$ & $0.462(0.092)$ & $0.757(0.073)$ & $0.855(0.050)$ \\
\hline $\mathrm{AOL}$ & $0.646(0.079)$ & $0.816(0.085)$ & $0.833(0.055)$ & $0.633(0.083)$ & 0.807 (0.089) & $0.859(0.052)$ \\
\hline
\end{tabular}

\begin{tabular}{|c|c|c|}
\hline & \multicolumn{2}{|c|}{ Reads $(\%, n=186)$} \\
\hline & First Reading & Second Reading \\
\hline \multicolumn{3}{|l|}{$\mathrm{mTICl}$} \\
\hline 0 & $12(6.45)$ & $13(6.99)$ \\
\hline 1 & $16(8.60)$ & $13(6.99)$ \\
\hline $2 a^{a}$ & $42(22.58)$ & $25(13.44)$ \\
\hline $2 b$ & $82(44.09)$ & $98(52.69)$ \\
\hline 3 & 34 (18.28) & $37(19.89)$ \\
\hline \multicolumn{3}{|l|}{$\mathrm{AOL}$} \\
\hline 0 & $12(6.45)$ & $12(6.45)$ \\
\hline 1 & $7(3.76)$ & $10(5.38)$ \\
\hline 2 & 31 (16.67) & $28(15.05)$ \\
\hline 3 & 136 (73.12) & 136 (73.12) \\
\hline
\end{tabular}

server agreement for 49 cases with BAO was not significantly different from that for all 62 patients. For the dichotomized scales, there was an increasing trend of $\kappa$ values in the AOL, but not in the mTICI scale.

Table 4 shows the distribution of all reads by using either the mTICI or the AOL scale. In 2 consecutive readings, there was a significant decrease in the proportion of mTICI $2 \mathrm{a}(42 / 186$, $22.58 \%$, in the first session versus $25 / 186,13.44 \%$, in the second session; $P<.03$ ) and a reciprocal increment in the sum of proportions for mTICI $2 \mathrm{~b}$ and mTICI $3(116 / 186,62.37 \%$, in the first session versus $135 / 186,72.58 \%$, in the second session; $P<.046$ ). In the proportion of unanimity, the mTICI was also significantly lower than the AOL $(14 / 62,23 \%$, in mTICI, versus $44 / 62,71 \%$, in the AOL; $P<.001)$.

\section{DISCUSSION}

In the 17 recent studies regarding intra-arterial thrombolysis in acute posterior circulation stroke, ${ }^{13-29} 5$ (29.4\%) did not provide any scheme and $12(70.6 \%)$ used the TIMI or TICI scale, of which $58 \%$ (7/12) used TIMI $\geq 2$ and $42 \%$ (5/12), TICI $\geq 2 \mathrm{~b}$ as a cutoff level of "successful reperfusion." In 10 studies with only BAO cases, ${ }^{14,17,20-23,25,27-29}$ the TIMI scale was used in 5 and the TICI scale in 4 . However, observer reliability tests in those previous studies had never been performed for angiographic assessment of posterior circulation stroke. If such heterogeneous and inconsistent scoring systems are used in defining end points of revascularization success, it is difficult to compare or combine results of clinical studies. ${ }^{30}$ Therefore, selection of a reliable biomarker for revascularization is relevant to the prediction of procedural efficacy and the outcome in posterior circulation stroke. To our knowledge, this is the first study to evaluate inter- and intraobserver agreement for 2 common scales in the angiographic evaluation following intra-arterial thrombolysis of posterior circulation stroke.
In this study, we found the observer variability of the mTICI inherent in the angiographic assessment of posterior circulation stroke. While inter- and intraobserver variability for the AOL was reliable, the mTICI failed to achieve substantial interobserver agreement with a low concordance rate of $23 \%$ (14/62 cases). We also demonstrated a significant difference in the proportion of mTICI 2 a reads that had a direct influence on the sum of proportions of mTICI $2 b$ and 3, which may affect the judgment of angiographic end points in intra-arterial thrombolysis. The mTICI was inferred inferior to the AOL for the following reason ${ }^{1}$ : the relative complexity of the mTICI with more responses and semiquantitative descriptors. Gaha et $\mathrm{al}^{4}$ explained that inter- and intraobserver disagreement in adjudicating treatment results may be caused by multiple problems: intrinsic ambiguities in the definitions of the classifications; discrepancies in the various ways the definitions are interpreted by various readers; and even if the definitions were understood in the same way, discrepancies in applying the definitions to individual cases. Kundel and Polansky ${ }^{31}$ also showed that the $\kappa$ value in observer agreement was likely to increase as the number of categories decreased. ${ }^{2}$ It is possible to have inconsistency in interpreting the mTICI 2 grade, such as mTICI $2 \mathrm{a}$ versus mTICI $2 \mathrm{~b}$, especially for posterior circulation. In fact, angiographic evaluation of the vertebrobasilar territory has some limitations, such as interference with abundant collateral flows, incomplete visualization of the perforating arteries to the brain stem, and the necessity to consider the antegrade flow from the anterior circulation.

Because endovascular revascularization therapy is becoming the main strategy for acute ischemic stroke, it is important to use the optimal scale with high reliability in decisions of revascularization end points. In fact, revascularization can be understood as angiographic recanalization of the primary arterial occlusive lesion or reperfusion in the arterial bed distal to the occlusion (TIMI, TICI, mTICI). The AOL scale has been the sole scoring system for measuring the degree of recanalization at the target arterial lesion since its introduction in the Interventional Management of Stroke trials, ${ }^{32-34}$ and the posterior circulation occlusions were categorized according to AOL recanalization in Interventional Management of Stroke III. ${ }^{32}$ Although Gaha et $\mathrm{al}^{4}$ reported that observer variability for the AOL was "moderate" in anterior circulation stroke, we found that this scheme had high reliability in posterior circulation stroke. Considering its ease of use and consistency, it is possible to evaluate the AOL as a recanalization scale in a further posterior circulation stroke study.

This study had some limitations. First, the study design was retrospective with a limited number of cases. Second, the predictive power of both scales in this study was not analyzed due to the sampling heterogeneity. In fact, whether to choose the recanalization or reperfusion scale as a determinant of clinical outcome in posterior circulation stroke is still controversial. Cho et $\mathrm{al}^{35}$ re- 
ported that reperfusion was a reliable surrogate and the strongest predictor of clinical outcome in anterior circulation stroke, and Singer et $\mathrm{al}^{36}$ reported that independent predictors of clinical outcome were not the TICI scale, but the collateral status in BAO. In contrast, Mourand et $\mathrm{al}^{37}$ proposed a DWI brain lesion score for prediction of clinical outcome in patients with BAO by using brain MR imaging. Finally, unfortunately in this study, only bilateral vertebral angiographies were used for interpretation, which may cause underdiagnosis of the mTICI because of the imperfect evaluation of collateral flows from the circle of Willis circulation.

\section{CONCLUSIONS}

In angiographic assessment of posterior circulation stroke, this is the first study to evaluate inter- and intraobserver variability for 2 commonly used scales; while the AOL as a recanalization scale showed a higher reliability, the mTICI, as a reperfusion criterion, failed to achieve substantial interobserver agreement among readers. In future studies, it will be necessary to validate the clinical impact of this result in posterior circulation stroke.

\section{ACKNOWLEDGMENTS}

We thank Kyung Hwa Han, MS, for her assistance with statistics for this study.

\section{REFERENCES}

1. Berkhemer OA, Fransen PS, Beumer D, et al. A randomized trial of intraarterial treatment for acute ischemic stroke. N Engl J Med 2015; 372:11-20 CrossRef Medline

2. Campbell BC, Mitchell PJ, Kleinig TJ, et al; EXTEND-IA Investigators. Endovascular therapy for ischemic stroke with perfusion-imaging selection. $N$ Engl J Med 2015;372:1009-18 CrossRef Medline

3. Goyal M, Demchuk AM, Menon BK, et al; ESCAPE Trial Investigators. Randomized assessment of rapid endovascular treatment of ischemic stroke. N Engl J Med 2015;372:1019-30 CrossRef Medline

4. Gaha M, Roy C, Estrade L, et al. Inter- and intraobserver agreement in scoring angiographic results of intra-arterial stroke therapy. AJNR Am J Neuroradiol 2014;35:1163-69 CrossRef Medline

5. Suh SH, Cloft HJ, Fugate JE, et al. Clarifying differences among Thrombolysis in Cerebral Infarction scale variants: is the artery half open or half closed? Stroke 2013;44:1166-68 CrossRef Medline

6. Bar M, Mikulik R, Jonszta T, et al. Diagnosis of recanalization of the intracranial artery has poor inter-rater reliability. AJNR Am J Neuroradiol 2012;33:972-74 CrossRef Medline

7. Tomsick T. TIMI, TIBI, TICI: I came, I saw, I got confused. AJNR Am J Neuroradiol 2007;28:382-84 Medline

8. Kallmes DF. TICI: if you are not confused, then you are not paying attention. AJNR Am J Neuroradiol 2012;33:975-76 CrossRef Medline

9. Zaidat OO, Yoo AJ, Khatri P, et al; Cerebral Angiographic Revascularization Grading (CARG) Collaborators, STIR Revascularization working group, STIR Thrombolysis in Cerebral Infarction (TICI) Task Force. Recommendations on angiographic revascularization grading standards for acute ischemic stroke: a consensus statement. Stroke 2013;44:2650 -63 CrossRef Medline

10. Gerber JC, Miaux YJ, von Kummer R. Scoring flow restoration in cerebral angiograms after endovascular revascularization in acute ischemic stroke patients. Neuroradiology 2015;57:227-40 CrossRef Medline

11. Khatri P, Neff J, Broderick JP, et al; IMS-I Investigators. Revascularization end points in stroke interventional trials: recanalization versus reperfusion in IMS-I. Stroke 2005;36:2400-03 CrossRef Medline
12. Landis JR, Koch GG. The measurement of observer agreement for categorical data. Biometrics 1977;33:159-74 CrossRef Medline

13. Becker KJ, Monsein LH, Ulatowski J, et al. Intraarterial thrombolysis in vertebrobasilar occlusion. AJNR Am J Neuroradiol 1996;17: 255-62 Medline

14. Egan R, Clark W, Lutsep H, et al. Efficacy of intraarterial thrombolysis of basilar artery stroke. J Stroke Cerebrovasc Dis 1999;8:22-27 CrossRef Medline

15. Lin DD, Gailloud P, Beauchamp NJ, et al. Combined stent placement and thrombolysis in acute vertebrobasilar ischemic stroke. AJNR Am J Neuroradiol 2003;24:1827-33 Medline

16. Macleod MR, Davis SM, Mitchell PJ, et al. Results of a multicentre, randomised controlled trial of intra-arterial urokinase in the treatment of acute posterior circulation ischaemic stroke. Cerebrovasc Dis 2005;20:12-17 CrossRef Medline

17. Bergui M, Stura G, Daniele D, et al. Mechanical thrombolysis in ischemic stroke attributable to basilar artery occlusion as first-line treatment. Stroke 2006;37:145-50 CrossRef Medline

18. Schulte-Altedorneburg G, Hamann GF, Mull M, et al. Outcome of acute vertebrobasilar occlusions treated with intra-arterial fibrinolysis in 180 patients. AJNR Am J Neuroradiol 2006;27:2042-47 Medline

19. Lutsep HL, Rymer MM, Nesbit GM. Vertebrobasilar revascularization rates and outcomes in the MERCI and multi-MERCI trials. $J$ Stroke Cerebrovasc Dis 2008;17:55-57 CrossRef Medline

20. Pfefferkorn T, Mayer TE, Opherk C, et al. Staged escalation therapy in acute basilar artery occlusion: intravenous thrombolysis and ondemand consecutive endovascular mechanical thrombectomy: preliminary experience in 16 patients. Stroke 2008;39:1496-500 CrossRef Medline

21. Nagel S, Schellinger PD, Hartmann M, et al. Therapy of acute basilar artery occlusion: intraarterial thrombolysis alone vs bridging therapy. Stroke 2009;40:140 - 46 CrossRef Medline

22. Schonewille WJ, Wijman CA, Michel P, et al; BASICS study group. Treatment and outcomes of acute basilar artery occlusion in the Basilar Artery International Cooperation Study (BASICS): a prospective registry study. Lancet Neurol 2009;8:724-30 CrossRef Medline

23. Yu YY, Niu L, Gao L, et al. Intraarterial thrombolysis and stent placement for acute basilar artery occlusion. J Vasc Interv Radiol 2010;21:1359-63 CrossRef Medline

24. Roth C, Mielke A, Siekmann R, et al. First experiences with a new device for mechanical thrombectomy in acute basilar artery occlusion. Cerebrovasc Dis 2011;32:28-34 CrossRef Medline

25. Andersson T, Kuntze Söderqvist $\AA$, Söderman M, et al. Mechanical thrombectomy as the primary treatment for acute basilar artery occlusion: experience from 5 years of practice. J Neurointerv Surg 2013;5:221-25 CrossRef Medline

26. Espinosa de Rueda M, Parrilla G, Zamarro J, et al. Treatment of acute vertebrobasilar occlusion using thrombectomy with stent retrievers: initial experience with 18 patients. AJNR Am J Neuroradiol 2013;34:1044-48 CrossRef Medline

27. Mordasini P, Brekenfeld C, Byrne JV, et al. Technical feasibility and application of mechanical thrombectomy with the Solitaire FR Revascularization device in acute basilar artery occlusion. AJNR Am J Neuroradiol 2013;34:159-63 CrossRef Medline

28. Möhlenbruch M, Stampfl S, Behrens L, et al. Mechanical thrombectomy with stent retrievers in acute basilar artery occlusion. AJNR Am J Neuroradiol 2014;35:959-64 CrossRef Medline

29. Mourand I, Machi P, Milhaud D, et al. Mechanical thrombectomy with the Solitaire device in acute basilar artery occlusion. J Neurointerv Surg 2014;6:200-4 CrossRef Medline

30. Fugate JE, Klunder AM, Kallmes DF. What is meant by “TICI"? AJNR Am J Neuroradiol 2013;34:1792-97 CrossRef Medline

31. Kundel HL, Polansky M. Measurement of observer agreement. $R a$ diology 2003;228:303-08 CrossRef Medline

32. Broderick JP, Palesch YY, Demchuk AM, et al; Interventional Management of Stroke (IMS) III Investigators. Endovascular therapy af- 
ter intravenous t-PA versus t-PA alone for stroke. $N$ Engl J Med 2013;368:893-903 CrossRef Medline

33. Tomsick T, Broderick J, Carrozella J, et al; Interventional Management of Stroke II Investigators. Revascularization results in the Interventional Management of Stroke II trial. AJNR Am J Neuroradiol 2008;29:582-87 CrossRef Medline

34. Tomsick TA, Yeatts SD, Liebeskind DS, et al; IMS III Investigators. Endovascular revascularization results in IMS III: intracranial ICA and M1 occlusions. J Neurointerv Surg 2014 Oct 23. [Epub ahead of print] CrossRef Medline

35. Cho TH, Nighoghossian N, Mikkelsen IK, et al. Reperfusion within 6 hours outperforms recanalization in predicting penumbra salvage, lesion growth, final infarct, and clinical outcome. Stroke 2015;46: 1582-89 CrossRef Medline

36. Singer OC, Berkefeld J, Nolte CH, et al; ENDOSTROKE Study Group. Mechanical recanalization in basilar artery occlusion: the ENDOSTROKE study. Ann Neurol 2015;77:415-24 CrossRef Medline

37. Mourand I, Machi P, Nogue E, et al. Diffusion-weighted imaging score of the brain stem: a predictor of outcome in acute basilar artery occlusion treated with the Solitaire FR device. AJNR Am J Neuroradiol 2014;35:1117-23 CrossRef Medline 